\author{
Research Article
}

Humaira Rizwana* and Mona S. Alwhibi

\title{
Biosynthesis of silver nanoparticles using leaves of Mentha pulegium, their characterization, and antifungal properties
}

https://doi.org/10.1515/gps-2021-0079

received September 26, 2021; accepted November 09, 2021

Abstract: Currently, the prime focus in agricultural research is on sustainability and protection of agricultural produce with minimal use of synthetic fungicides. In the present study, silver nanoparticles (AgNPs) were synthesized using fresh leaves of Mentha pulegium (M.p) through a simple, easy, and economical method. The formation of M.p-AgNPs was ascertained with UV-visible spectroscopy that gave a surface plasmon resonance peak at $430 \mathrm{~nm}$. Further, M.p-AgNPs were characterized by energy dispersive X-Ray analysis (EDX), transmission electron microscopy (TEM), dynamic light scattering, and Fourier-transform infrared (FTIR) spectroscopy. The DLS spectrum and TEM microphotographs showed that the M.p-AgNPs were small in size, measuring between 4 and $60 \mathrm{~nm}$. Significant hyphal growth inhibition of some selected fungal phytopathogens was achieved after exposing them to various concentrations of M.p-AgNPs. The M.p-AgNPs $\left(40 \mu \mathrm{g} \cdot \mathrm{mL}^{-1}\right)$ suppressed the fungal mycelial growth of all the test isolates significantly. When compared to the control, Fusarium solani (63\% inhibition) and Alternaria alternata (61\% inhibition) showed the highest inhibition. Likewise, spore germination was inhibited in a potent manner. Hence, based on the findings of the present study, M.p-AgNPs can be used to create a low cost, nontoxic, eco-friendly fungicide to control the growth and proliferation of some fungal phytopathogens in the agricultural sector.

Keywords: Mentha pulegium, fungal plant pathogens, green silver nanoparticles, antifungal activity

\footnotetext{
* Corresponding author: Humaira Rizwana, Department of Botany and Microbiology, College of Science, King Saud University, P.O. Box 22452, Riyadh 11495, Saudi Arabia,

e-mail: hrizwana@ksu.edu.sa

Mona S. Alwhibi: Department of Botany and Microbiology, College of Science, King Saud University, P.O. Box 22452, Riyadh 11495, Saudi Arabia
}

\section{Introduction}

Nanotechnology is a cutting-edge technology that has rapidly evolved in recent years, resulting in a slew of new breakthroughs in medicine, agronomy, engineering, biosciences, and physics [1]. The nanotechnique entails the controlled synthesis of extremely tiny particles using various metals. The nanoparticles (NPs) created have distinct properties, shapes, and sizes range from 1 to $100 \mathrm{~nm}$ [2]. However, silver nanoparticles (AgNPs) are the most studied of all metals. AgNPs are being researched and used extensively in various therapies, including bone and wound healing, vaccine adjuvants, and bioimaging [3]. Furthermore, these particles have demonstrated significant inhibition of pathogenic microbes and cancer cells [3-5].

The conventional methods of NP synthesis (chemical and physical) are the most used approaches because they allow control over the shape and size of the particles [6]. However, these methods are expensive and use some toxic components that have a negative impact on the environment. All these characteristics limit their use in many scientific applications and have created a great deal of ambiguity. Conversely, the biological method of NP synthesis is a simple, cost-effective, environmentally friendly, and effective method that uses readily available natural materials and does not necessitate elaborate processing [7]. The biological method of synthesis is also referred to as green synthesis, and it involves organisms as whole cells or biomolecules from plant extracts [8].

Plants are a treasure trove for a variety of biomolecules. Plant secondary metabolites play an important role in reduction and capping during the nanosynthesis process $[9,10]$. The production of NPs from various plant parts is a simple and expeditious process. Furthermore, the NPs created are nontoxic and biocompatible and have improved stability [11]. Recent research has demonstrated the green synthesis of AgNPs, as well as their antimicrobial activities $[12,13]$. 
Mentha pulegium L. (M.p) is a perennial aromatic and tomentose herb belonging to the family Lamiaceae [14]. It is native to Central Asia, the Middle East, North Africa, and Europe [15,16]. In the Kingdom of Saudi Arabia, M.p leaves are popularly known as Mint of Al Medina. The M.p leaves grown in Medina are small and ovate and have a very strong aroma and flavor. The leaves are mostly consumed in fresh forms in herbal tea and culinary applications, whereas the dry leaves are mostly used as an additive in several spices. In folk medicine, M.p leaves are used to treat nausea, bloating, dyspepsia, diarrhea, gastrointestinal ailments, headaches, cough and influenza, and tuberculosis [17-19]. Its antibacterial [20,21], antigenotoxic [22], and antioxidant activities [23] have also been reported.

To the best of our knowledge, very few studies have documented the antifungal activity of AgNPs synthesized from M.p, especially from the leaves grown in Al-Madinah Al-Munawarah. Hence, with this assumption, this study aimed to synthesize AgNPs using M.p leaves, characterize the synthesized NPs, and evaluate their antifungal activity against some phytogenic fungi.

\section{Materials and methods}

All the chemicals and reagents used in this study were of analytical grade and were purchased from Sigma AldrichGermany. All the experimental preparations were carried out with double-distilled water, while antifungal studies were done with double-sterilized distilled water.

\subsection{Collection and identification of the plant}

M.p was purchased from a local market in Medina city, Kingdom of Saudi Arabia. The plant was identified by Professor Najat Bukhari and deposited in the herbarium of King Saud University (Department of Botany), College of Science, Saudi Arabia, under the voucher no. 24543.

\subsection{Preparation of leaf extract}

M.p leaves were separated from the stem, washed, and shade dried at $25^{\circ} \mathrm{C}$. Leaves $(10 \mathrm{~g})$ were chopped finely and added to $100 \mathrm{~mL}$ of distilled water and mixed well. This mixture was heated at $60^{\circ} \mathrm{C}$ for $20 \mathrm{~min}$, allowed to cool, and then centrifuged at 5,000 rpm for $10 \mathrm{~min}$. The centrifuged solution was filtered through paper (Whatman No. 1). The filtrate was collected and used for further studies.

\subsection{Synthesis of silver nanoparticles (M.p-AgNPs)}

A $100 \mathrm{~mL}$ aqueous silver nitrate solution $\left(1 \mathrm{mM}-\mathrm{AgNO}_{3}\right)$ was prepared by adding $\mathrm{AgNO}_{3}$ powder to a fixed volume of distilled water. By adding $5 \mathrm{~mL}$ of M.p leaf extract to $45 \mathrm{~mL}$ of aqueous $\mathrm{AgNO}_{3}$ solution, a reaction mixture was prepared. This yellow-colored mixture was incubated at $80^{\circ} \mathrm{C}(\mathrm{pH} 8)$ for $30 \mathrm{~min}$ and observed for color change. When the mixture turned brown, it indicated the formation of M.p-AgNPs through the reduction of Ag ions.

\subsection{Characterization of the synthesized M.p-AgNPs}

The synthesized M.p-AgNPs were characterized and examined with UV-Vis, transmission electron microscope (TEM), DLS, EDX, and Fourier-transform infrared (FTIR) spectroscopy. UV-Vis spectroscopy was used to obtain the absorption spectrum (Perkin Elmer, MA, USA). The morphology of M.p-AgNPs and their size were examined and photographed under a transmission electron microscope (TEM; JEOL-JEM-Plus-1400, Japan). The polydiversity index, hydrodynamic diameter, and size distribution of M.p-AgNPs were determined with a dynamic light scattering (DLS) analyzer (Malvern-model ZEN-3600, Nano series, Malvern-UK). Furthermore, the elemental composition of M.p-AgNPs was examined, and the spectrum was captured at an accelerating voltage $(30 \mathrm{kV})$ with the help of an energy dispersive X-ray detector (EDX-FESEM-model no-JSM-7610F, Japan). FTIR analysis of M.p leaf extract and M.p-AgNPs was investigated using the potassium bromide pellet on a Thermo Fischer Spectrometer (Thermo Scientific Model-Nicolet 6700, USA). The IR spectrum was collected at a wavelength range of $400-4,000 \mathrm{~cm}^{-1}$.

\subsection{Phytopathogens}

The following phytopathogens were used in the present study: Alternaria alternata, Colletotrichum musae, Fusarium 
solani, F. oxysporum, Helminthosporium sativum, and Macrophomina phaseolina. The fungal isolates $H$. sativum, M. phaseolina, and C. musae were provided by the Department of Plant Protection, College of Food and Agricultural Sciences, while $A$. alternata, $F$. solani, and $F$. oxysporum were obtained from the Department of Botany and Microbiology, College of Science, King Saud University.

\subsection{Determination of antifungal activity}

The synthesized M.p-AgNPs were evaluated against the aforementioned fungal pathogens at different concentrations $\left(5,10,20\right.$, and $\left.40 \mu \mathrm{g} \cdot \mathrm{mL}^{-1}\right)$. The assay was conducted according to the method of Kim et al. [24] with minor changes. In brief, different concentrations of M.p-AgNPs were added separately in a fixed volume to potato dextrose agar (PDA), mixed well by swirling, and the media amended with NPs was carefully added to Petri dishes.

After an hour, $6 \mathrm{~mm}$ fungal agar discs were removed aseptically from the respective fungal culture plates and placed in the center of each Petri plate. Plates containing PDA and mycelial discs without M.p-AgNPs served as positive controls, while plates amended with the fungicide (instead of M.p-AgNPs) served as negative controls. In this study, a combination of $0.1 \%$ carbendazim + mancozeb $(C+M)$ was used as a fungicide. All the inoculated plates were incubated at $28^{\circ} \mathrm{C}$ for 7 days. The diameter of the mycelial growth (colony) was measured on the seventh day and the percentage (\%) of mycelial inhibition was calculated:

$\%$ Mycelial inhibition $=($ Dic - Dit $) /$ Dic $\times 100$

where Dic represents the average mycelial growth in control plates and Dit represents the average colony diameter at each treatment.

\subsection{Effect of M.p-AgNPs on spore germination of test pathogens}

The assay for spore germination was conducted following the method of Ibrahim [25]. Different concentrations of M.p-AgNP in the range of $5,10,20$, and $40 \mu \mathrm{g} \cdot \mathrm{mL}^{-1}$ were prepared, tested, and observed for their effect on spore germination. Briefly, $500 \mu \mathrm{L}$ of each M.p-AgNP and spore suspension (spore density of $1 \times 10^{6}$ spores $\cdot \mathrm{mL}^{-1}$ ) were added to a test tube to obtain a final test concentration $\left(5-40 \mu \mathrm{g} \cdot \mathrm{mL}^{-1}\right)$. Similarly, the same volumes of spore suspension and distilled water in a test tube served as controls. All of the test tubes were placed in an incubator $\left(28^{\circ} \mathrm{C}\right)$ for $24 \mathrm{~h}$. Postincubation period, the spore germination rate was recorded. The spore germination was calculated by counting 100 spores (on a slide with lactophenol cotton blue) for each control and treatment, and the percentage inhibition rate was determined [26]. The experiment was repeated thrice with three replicates in each set.

\subsection{Statistical analysis}

The data presented in this study were analyzed by standard deviation and were determined by analysis of variance for significant differences $(p \leq 0.05)$ and Tukey's HSD test. The statistical tests were run on XLSTAT (software version 2020.1.1), Addinsoft Inc.

\section{Results}

\subsection{Synthesis of M.p-AgNPs}

When leaf extract of M.p (yellow) was added to colorless $\mathrm{AgNO}_{3}$ solution under facile conditions, the mixture turned brown in color after $45 \mathrm{~min}$ indicating the formation of M.p-AgNPs (Figure 1). The brown colored colloidal solution corresponds to the surface plasmon resonance (SPR), which is caused by the oscillation of free electrons in the electromagnetic field [27].

\subsection{UV-Vis analysis of biosynthesized NPs}

Figure 2 shows UV-Vis absorption spectrum of the biosynthesized AgNPs from M.p leaf extract. A distinct SPR peak at $430 \mathrm{~nm}$ confirmed the formation of M.p-AgNPs. The position of the peak (SPR) on the spectrum is determined by various factors and properties of NPs, including the refractive index of the medium and the size and shape of NPs [28,29]. Figure 2 depicts the reasonably broad and unique SPR peak, which is indicative of the size distribution of the synthesized M.p-AgNPs over a wide range. Similar findings have been reported earlier [30].

\subsection{FTIR analysis of plant extract and synthesized AgNPs}

Figures 3 and 4 depict the IR absorption spectrum of M.p leaf extract and synthesized M.p-AgNPs. The FTIR 


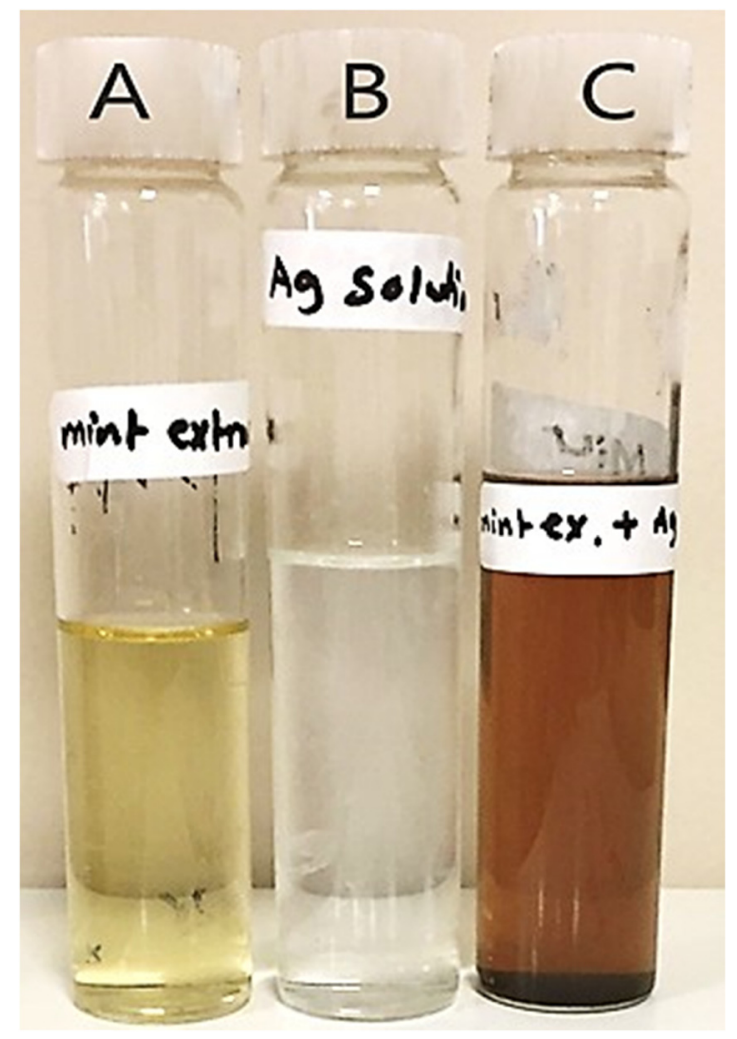

Figure 1: Formation of AgNPs using M.p aqueous leaf extract: A - M.p aqueous leaf extract, $B$ - silver nitrate solution, $C$ - synthesized M.p-AgNPs. spectrum of M.p leaf extract (Figure 3) showed a strong broad peak at $3,404 \mathrm{~cm}^{-1}$. This peak could be associated with the $\mathrm{OH}$ stretching vibrations of phenols and alcohols. The peaks observed at 2,933,1,606, and $1,521 \mathrm{~cm}^{1}$ denote the $\mathrm{CH}$ stretching of alkanes and symmetric $-\mathrm{NH}_{2}$ bending of amino acids. The peaks at 1,408, 1,265, and $1,067 \mathrm{~cm}^{-1}$ suggest the presence of aromatic compounds (C-C stretching) and symmetric and asymmetric stretches of C-O-C. Rad et al. [31] in a recent study characterized zinc NPs synthesized from M.p leaf extract and showed peaks at similar positions on the IR spectrum.

The FTIR spectrum of M.p-AgNP was significantly different from that of M.p leaf extract. The peaks at $3,446,1,622,1,384$, and $1,041 \mathrm{~cm}^{-1}$ shown in the FTIR spectrum of M.p-AgNP (Figure 4) indicate the presence of an $\mathrm{OH}$ group of alcohol or phenols, $-\mathrm{NH}$ group of amide or proteins, and carbonyl group of esters. These results strongly indicate the binding of $\mathrm{Ag}+$ to $\mathrm{OH}$ groups of phenol and alcohols and $\mathrm{C}=\mathrm{O}$ of esters or aldehydes and also confirm the capping and reduction of $\mathrm{Ag}+$ to AgNPs. The noticeable alterations in the vibrational bands and stretches in the IR of M.p-AgNP suggest that functional groups play a significant role in the capping and reduction processes during the synthesis of M.p-AgNP. The peaks observed in both spectra in the current study indicate the presence of several bioactive molecules such

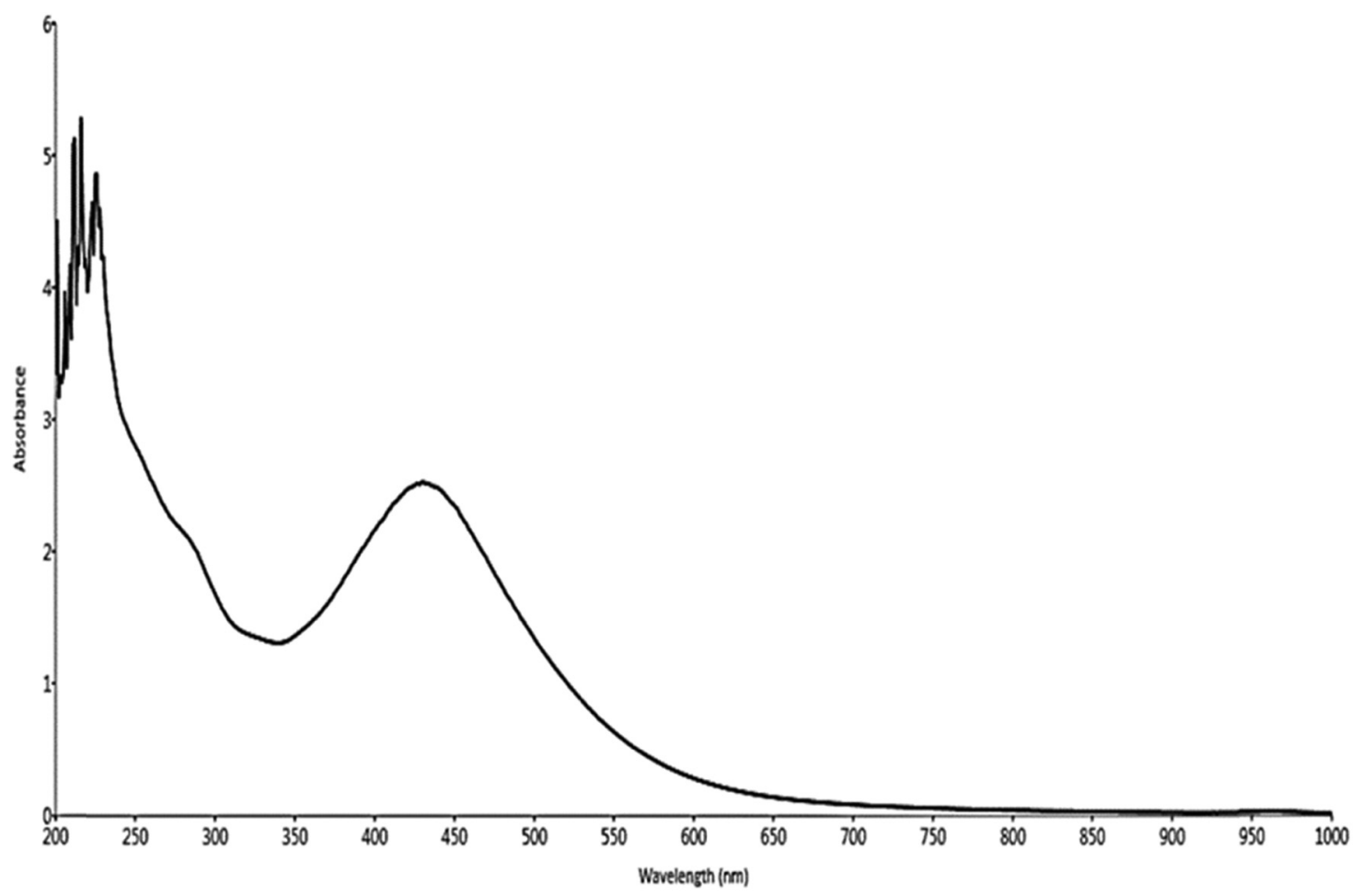

Figure 2: UV-Vis absorption spectrum of the biosynthesized AgNPs from aqueous leaf extracts of $M$. pulegium. 


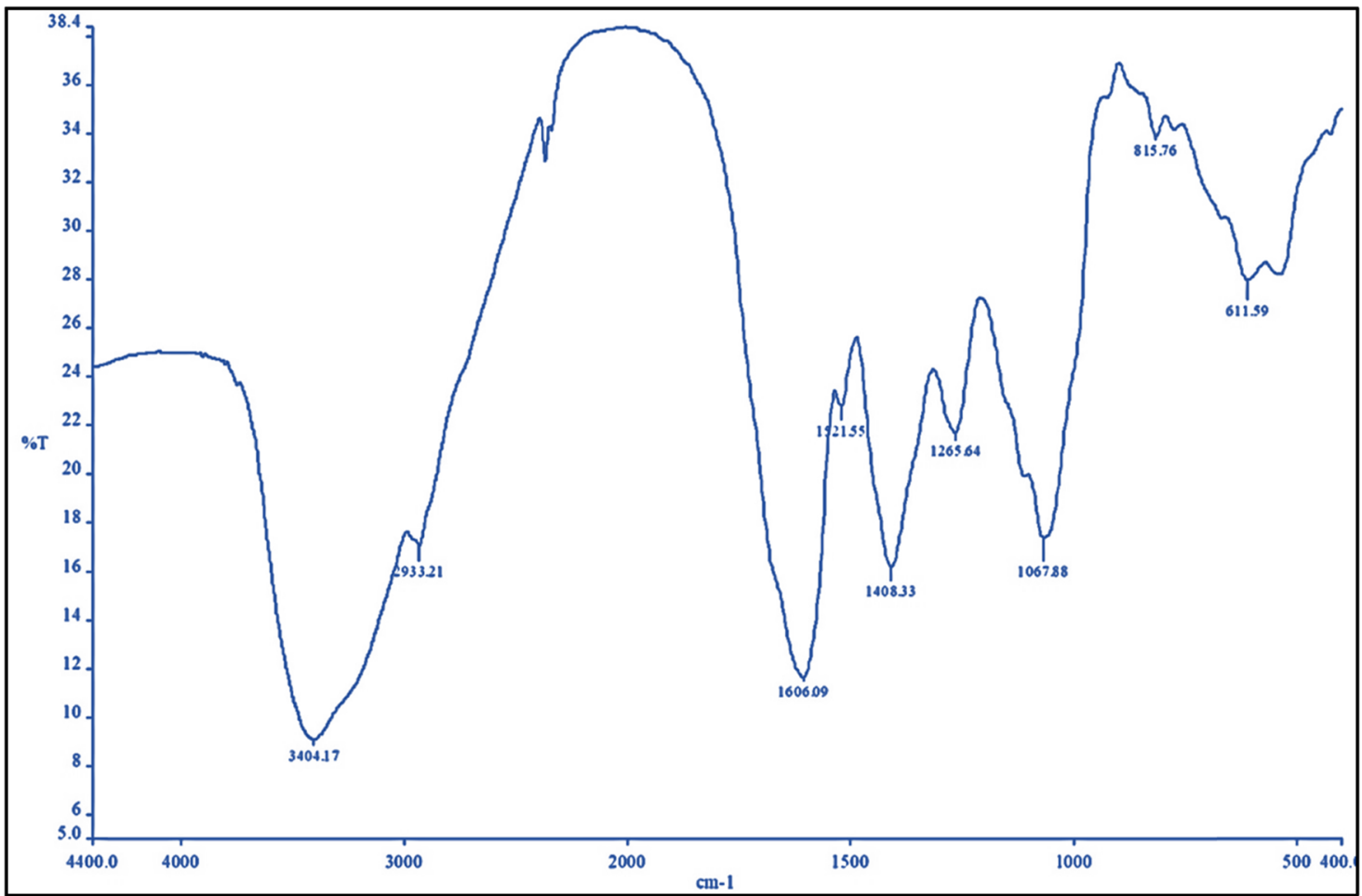

Figure 3: FTIR spectrum of M.p aqueous leaf extract.

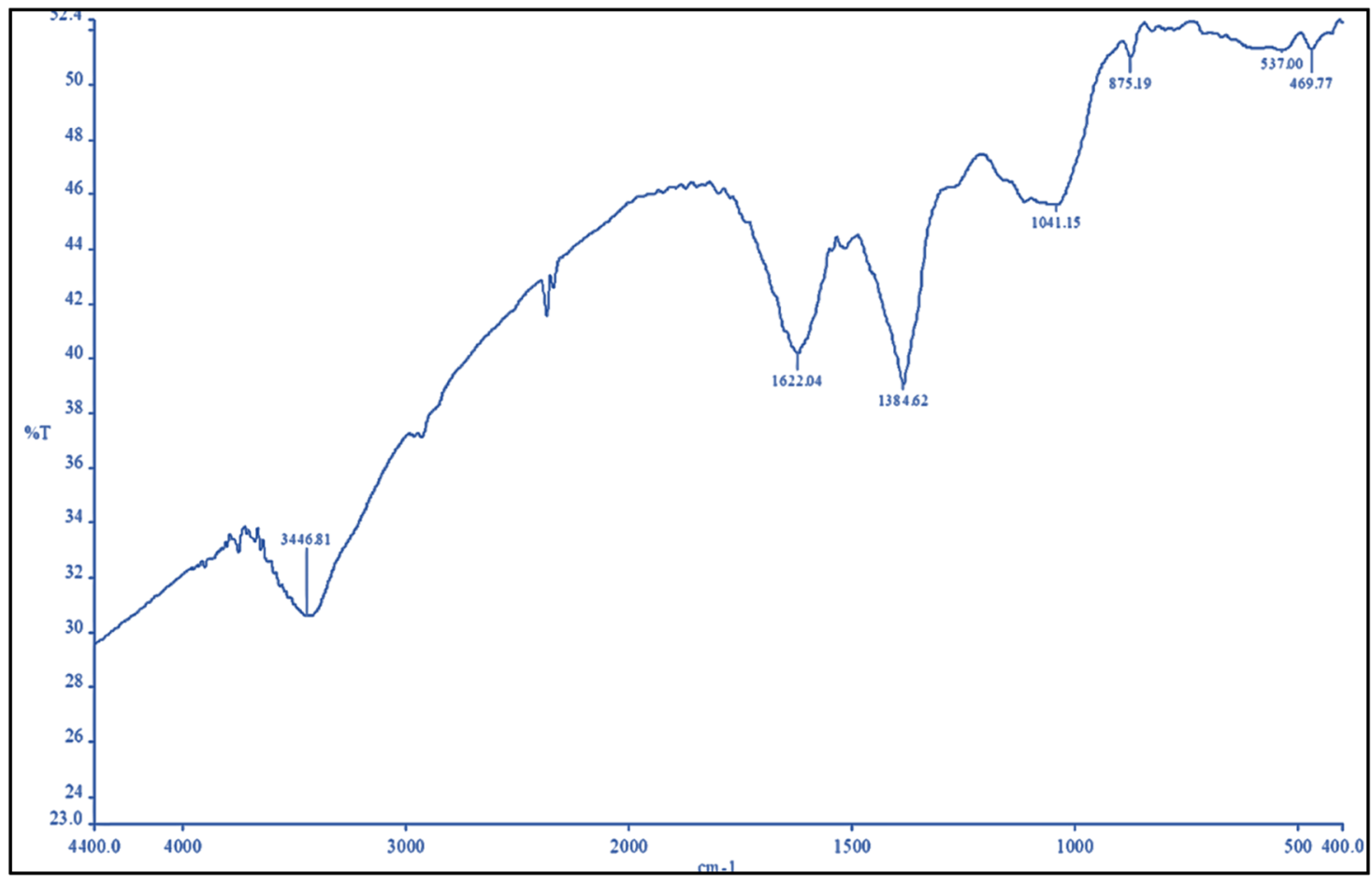

Figure 4: FTIR spectrum of the biosynthesized AgNPs of M.p-AgNPs.

as amines, proteins, phenols, and aromatic compounds. reduction, capping, and stabilization. Previous research These biomolecules are well recognized for their role in has demonstrated the role of carbonyl and hydroxyl various processes during the synthesis of NPs, such as groups in the aforementioned process involving the 
biosynthesis of green AgNPs [32,33]. Furthermore, the biomolecules present in plant extract prevent the agglomeration of NPs [33].

\subsection{DLS - measurement analysis}

The average size of biosynthesized M.p-AgNPs and their distribution were evaluated with the DLS analyzer. The pattern is depicted in Figure 5. The average size of the NPs was $61.81 \mathrm{~nm}$ while the polydiversity index was 0.233 . The low polydiversity index value and size distribution show that the particles are highly dispersed. DLS is an important technique that determines the hydrodynamic measurements of the NPs, in association with biological molecules and ions attached to the NPs $[34,35]$.

\subsection{TEM of biosynthesized M.p-AgNP}

Figure 6 depicts the microphotograph of biosynthesized M.p-AgNP. The synthesized M.p-AgNPs were chiefly spherical, and the mean diameter of the particles ranged between 4 and $46 \mathrm{~nm}$. The particles were widely separated without agglomeration. The current findings are consistent with those of Kelkawi et al. [36] who reported that the size of AgNPs synthesized by using M.p plant extract was in the
5-50 $\mathrm{nm}$ range and that their shape was anisotropic. The average diameter of M.p-AgNP measured with TEM was much smaller than that measured with DLS. This could be because TEM measures the NPs in their dry state, whereas DLS measures them in their hydrated state [37].

\subsection{Energy dispersive X-ray analysis-EDX}

The EDX spectrum of the synthesized M.p-AgNPs is depicted in Figure 7. The spectrum showed peaks between 2.5 and $3 \mathrm{keV}$, indicating silver signals and the formation of M.p-AgNP. The peak at $3 \mathrm{keV}$ is an accurate indication of the formation of AgNPs and is ascribed to the SPR [38]. The results indicate that M.p-AgNPs contained silver (23.9\%), along with other elements like carbon (42.9\%), oxygen $(30.7 \%)$, calcium $(0.04 \%)$, and potassium $(20 \%)$. The presence of elements other than silver could be from the biomolecules of leaf extract that get bound to NPs during synthesis or contaminants from the grid itself.

\subsection{Mycelial growth inhibition}

As depicted in Figures 8 and 9, all the fungal phytopathogens treated with M.p-AgNPs inhibited mycelial growth significantly $(p \geq 0.05)$. As the concentration of M.p-AgNPs

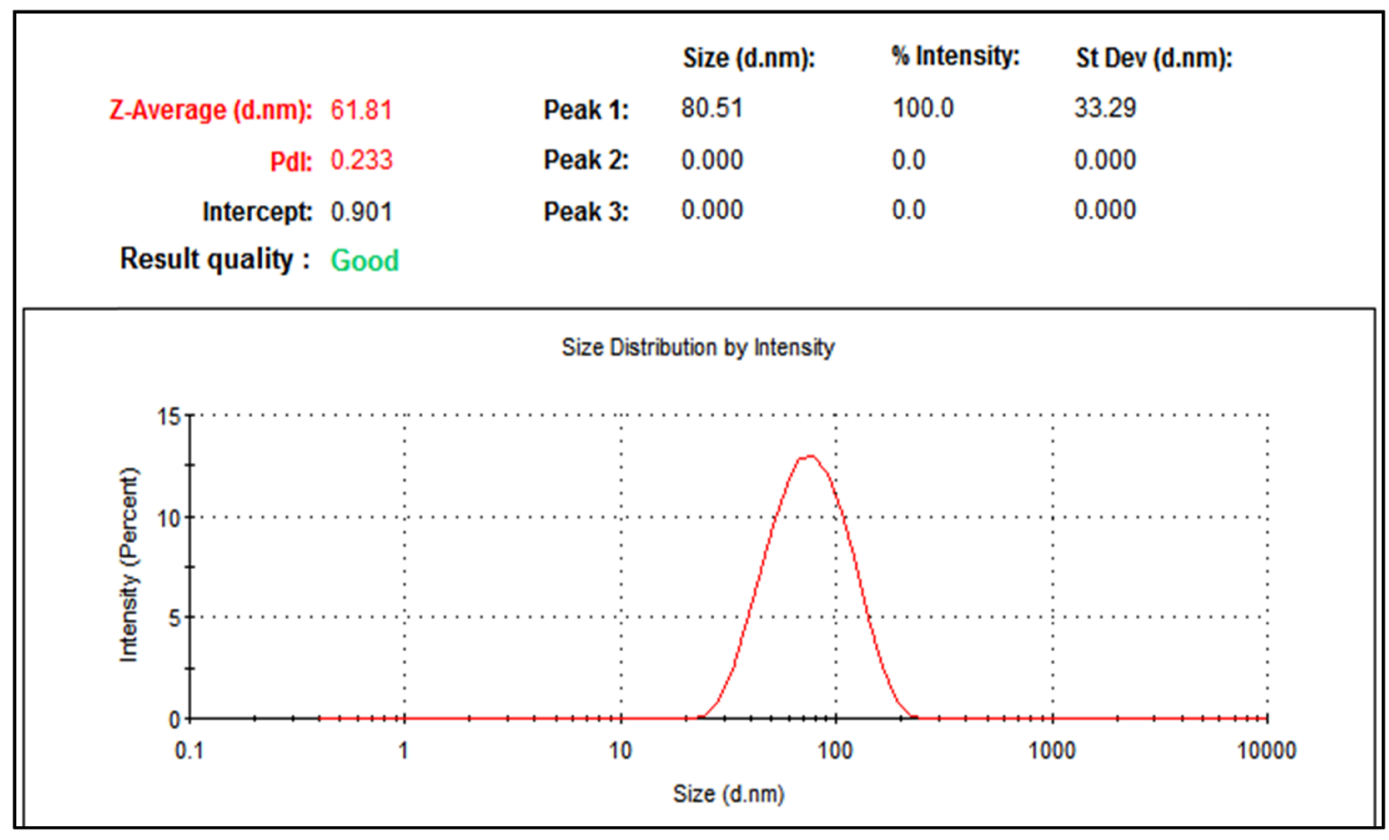

Figure 5: The DLS spectrum exhibiting the size range of synthesized M.p-AgNPs. 


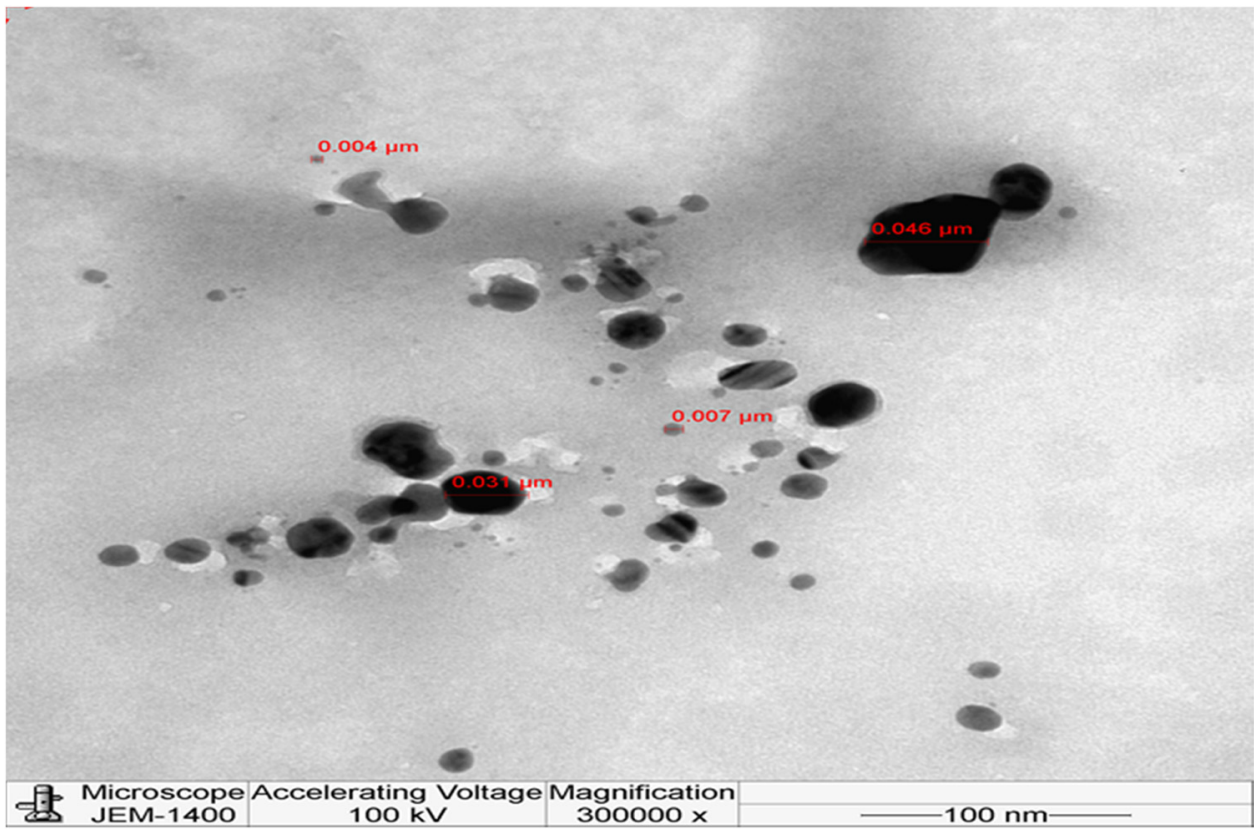

Figure 6: TEM microphotographs of the NPs synthesized using M.p leaf extracts.
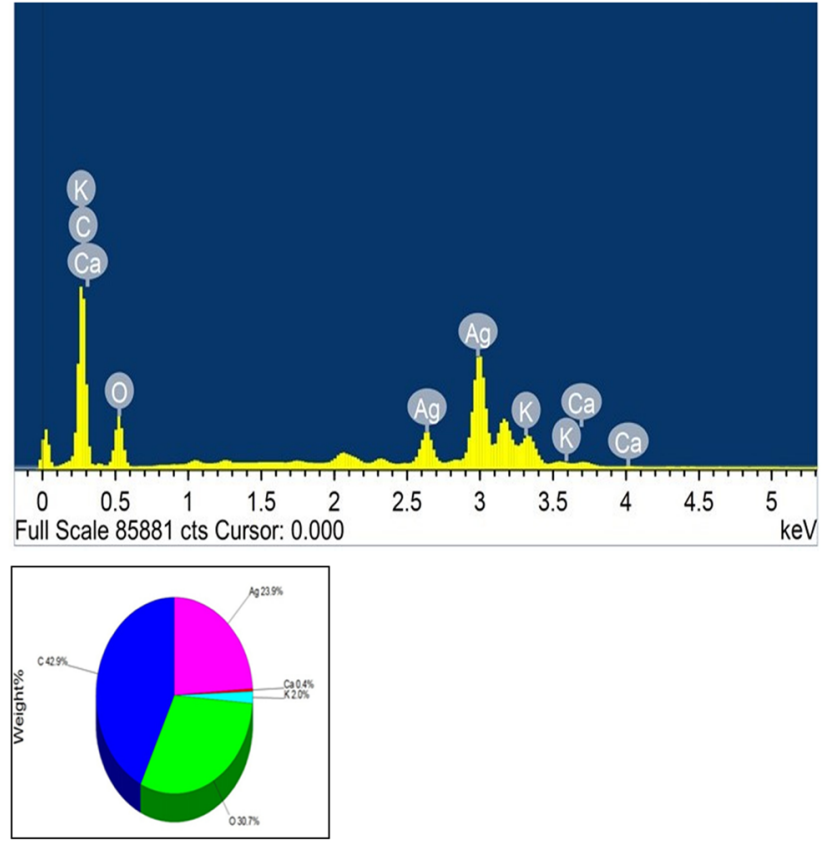

Figure 7: EDX spectrum of NPs synthesized from the leaves of M.p.

increased, so did the inhibitory activity. F. solani and $A$. alternaria had the smallest colony diameters at the highest test concentration $\left(40 \mu \mathrm{g} \cdot \mathrm{mL}^{-1}\right.$; Figure 8$)$. Similarly, at $40 \mu \mathrm{g} \cdot \mathrm{mL}^{-1}, F$. solani inhibited mycelial growth the most (66\%), followed by A. alternata (61\%), M. phaseolina (56\%), H. sativum (53\%), and F. oxysporum (51\%). C. musae, however, was least inhibited (36\%), even at the highest test concentration. Some isolates, like M. phaseolina and $F$. oxysporum, showed complete inhibition when treated with the fungicide (Figure 9). However, M.p leaf extract and $\mathrm{AgNO}_{3}$ had minimal growth inhibitory activity on all the test isolates. Overall, for all the plant pathogens tested, M.p-AgNPs caused considerable mycelial growth inhibition as compared to $\mathrm{AgNO}_{3}$ and extracts. M.p-AgNPs' large surface area and micro size allow them to easily penetrate cells through the cell membrane, causing cell damage $[39,40]$. However, the antifungal mechanism of NPs against plant pathogenic fungi remains unclear. Biosynthesized NPs are thought to be capable of crossing plant cell membrane barriers very meticulously via a very precise penetration technique. The rapid influx of NPs is thought to cause an electrolyte imbalance. Furthermore, the unchecked entry of NPs causes cell death by targeting the cellular proteins and the nucleic acids (DNA and RNA) [41,42].

\subsection{Spore germination}

Spores are very crucial in the growth of fungal pathogens as they germinate, spread, and penetrate the underlying tissue, thereby establishing the pathogen. Impeding the growth and germination of spores is vital for arresting the spread and establishment of any disease. Figure 10 illustrates the effective suppression of spore germination treated with M.p-AgNPs. The figure clearly shows that 


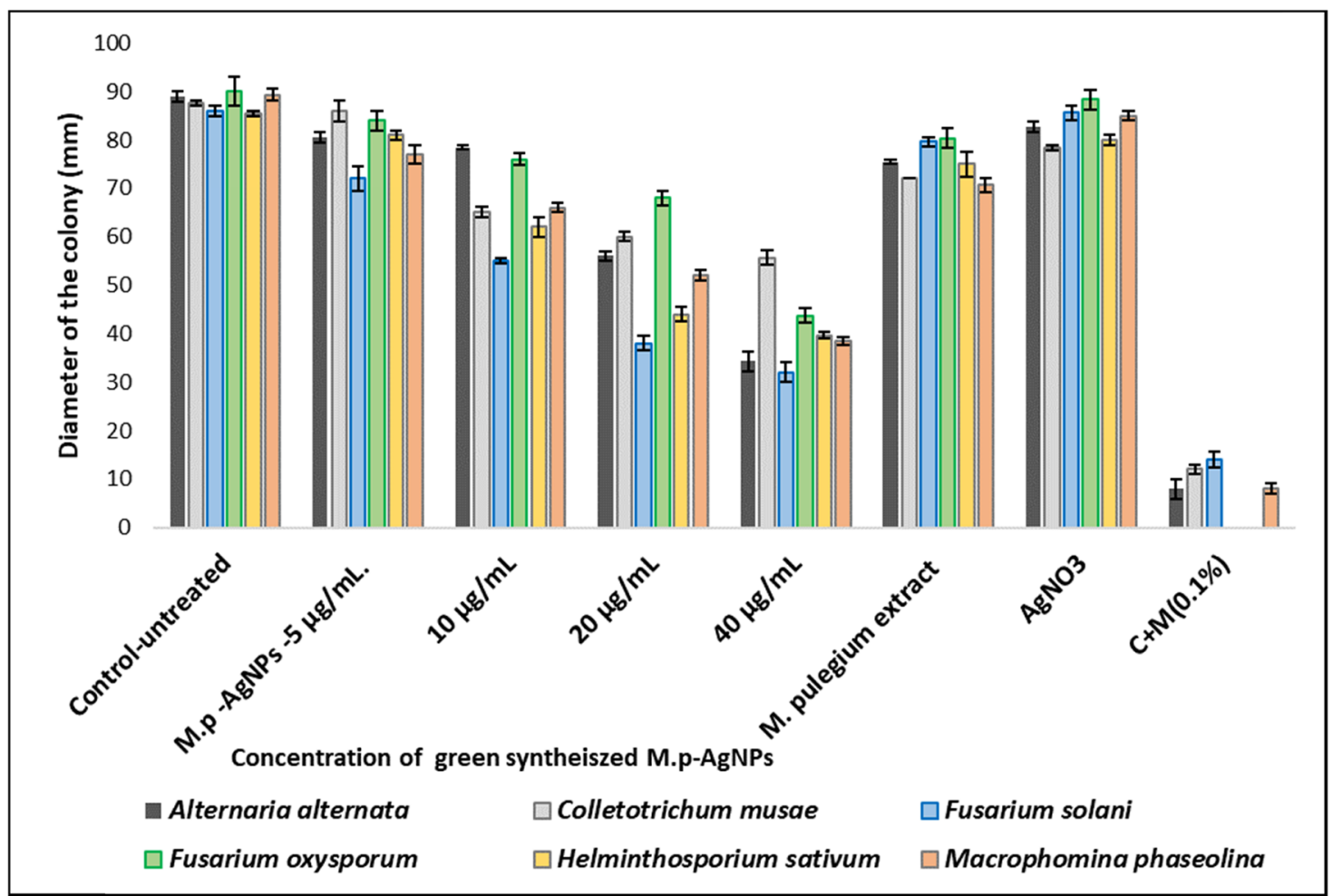

Figure 8: Antifungal activity of green-synthesized M.p-AgNPs.

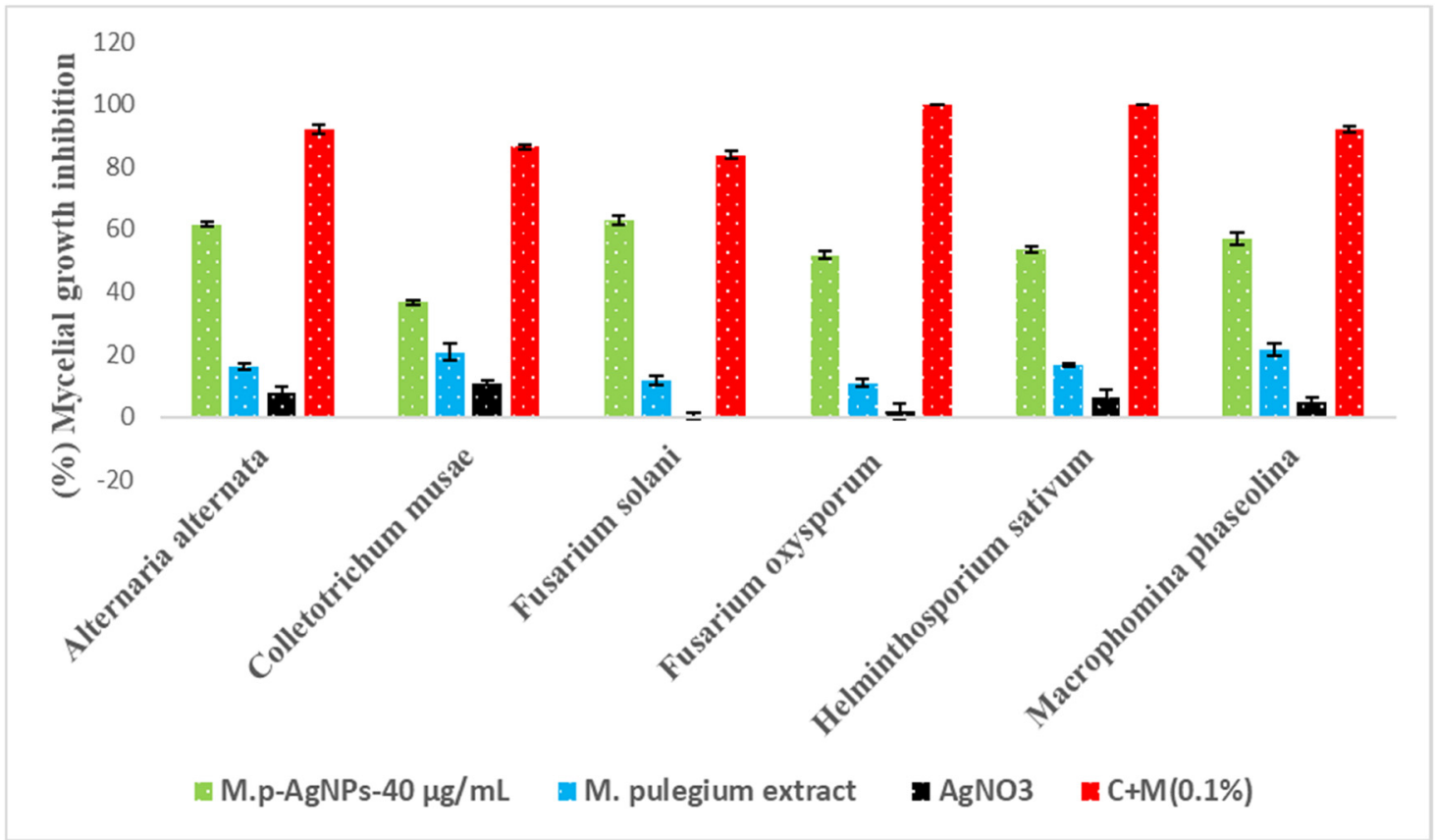

Figure 9: Mycelial growth inhibition of test pathogens treated with M.p-AgNPs at $40 \mu \mathrm{g} \cdot \mathrm{mL}^{-1}$.

at a concentration of $40 \mu \mathrm{g} \cdot \mathrm{mL}^{-1}, F$. solani, A. alternata, Sterilized distilled water had no effect on spore germiand M. phaseolina exhibited considerable inhibition of nation. $\mathrm{AgNO}_{3}$ and M.p leaf extract had a negligible effect spore germination $(18 \%, 22 \%$, and $24 \%$, respectively). on the inhibition of spore germination (Figure 10 ). 


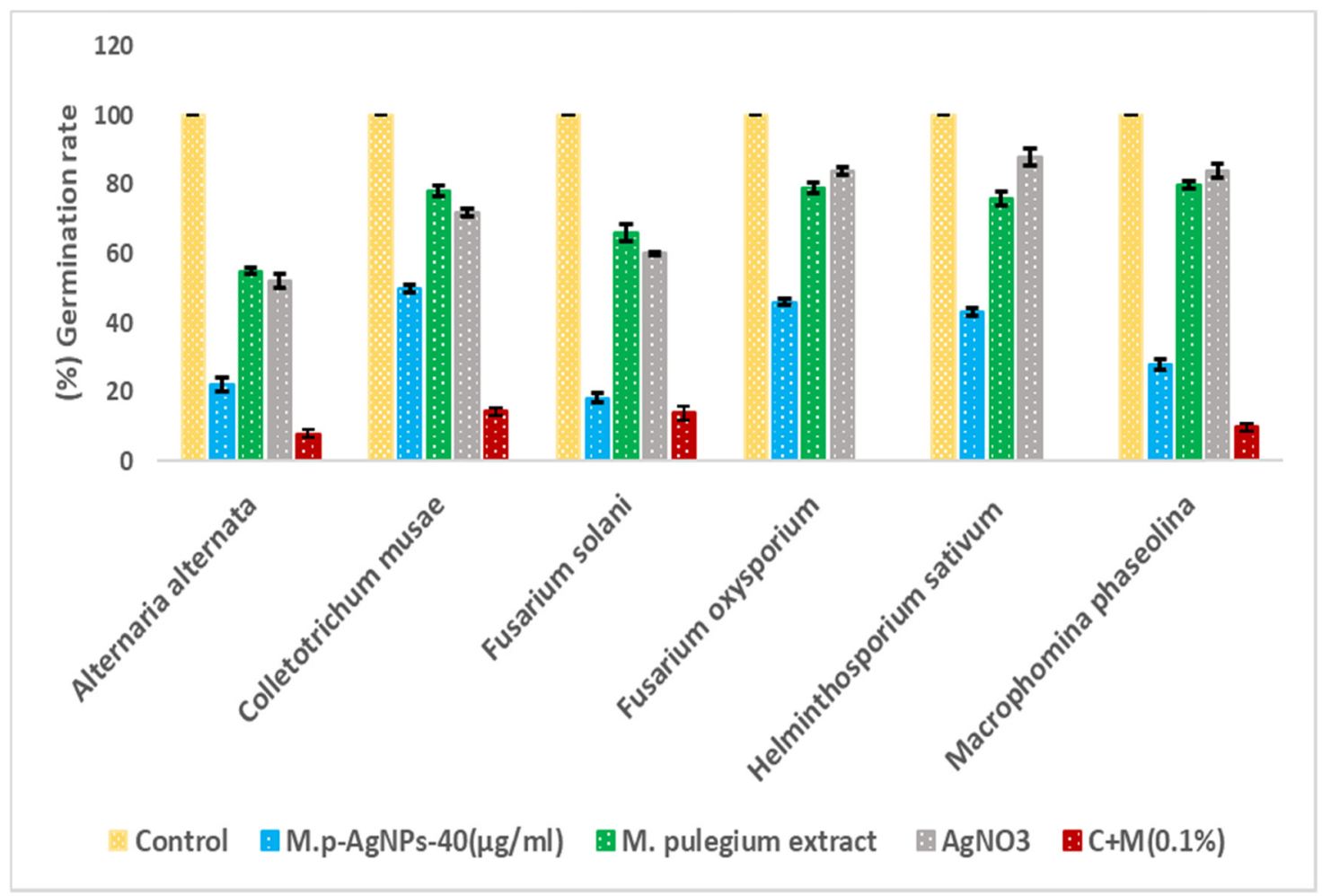

Figure 10: Percentage spore germination of fungal test pathogens treated with M.p-AgNPs at $40 \mu g \cdot \mathrm{mL}^{-1}$.

The current study clearly indicates the significant inhibition of mycelial growth and spore germination of plant pathogenic fungi treated with M.p-AgNPs. The small size of M.p-AgNPs along with the secondary metabolites present in the leaf extracts might have facilitated the robust inhibitory activity. In agreement with these findings, previous reports have demonstrated the antifungal activity of plant-derived AgNPs against an array of plant pathogenic fungi, including Colletotrichum sp., Aspergillus sp., and Fusarium sp. [43,44]. The variable inhibitory activity of M.p-AgNPs on the growth of fungal pathogens seen in this study could be due to the resistance offered by the fungal cell barriers that hinder the entry of NPs into the cell, thus reducing the extent of damage to fungal cells and spores.

\section{Conclusion}

Plant-derived NPs are used widely in a variety of bioscience applications around the world. AgNPs were successfully synthesized using M.p leaves in this study. The synthesized NPs were characterized, and their antifungal properties were evaluated. The biosynthesized M.p-AgNPs inhibited hyphal growth and suppressed spore germination of fungal test pathogens in a significant manner. The growing demand for a safe food supply has compelled the use of nontoxic agents to protect agricultural produce from devastating fungal pathogens. Based on the findings of this study, it is proposed that M.p-AgNPs can be formulated into a nontoxic fungicide to control plant pathogens at a low cost and in an environmentally friendly manner. More research is needed to understand their effect on human cells and to investigate their therapeutic applications.

Acknowledgements: The authors extend their appreciation to the Researchers Support Project (number RSP 2021/173) of King Saud University.

Funding information: The authors extend their appreciation to the Researchers Support Project (number RSP 2021/173) of King Saud University, Riyadh, Saudi Arabia, for payment of the charge for publishing this manuscript.

Author contributions: Humaira Rizwana: conceptualization, project administration, writing - original draft, writing review and editing, formal analysis; Mona S. Alwhibi: methodology, resources, writing - original draft, validation, and funding acquisition.

Conflict of interest: Authors state no conflict of interest. 


\section{References}

[1] Nicolas J, Mura S, Brambilla D, Mackiewicz N, Couvreur P. Design, functionalization strategies and biomedical applications of targeted biodegradable/biocompatible polymerbased nanocarriers for drug delivery. Chem Soc Rev. 2013;42(3):1147-235.

[2] Ahmed S, Chaudhry SA, Ikram S. A review on biogenic synthesis of $\mathrm{ZnO}$ nanoparticles using plant extracts and microbes: a prospect towards green chemistry. J Photochem Photobiol B Biol. 2017;166:272-84.

[3] Xu L, Wang YY, Huang J, Chen CY, Wang ZX, Xie H. Silver nanoparticles: synthesis, medical applications and biosafety. Theranostics. 2020;10(20):8996-9031. doi: 10.7150/thno.45413.

[4] Khan I, Saeed K, Khan I. Nanoparticles: properties, applications and toxicities. Arab J Chem. 2019;12(7):908-31. doi: 10.1016/j.arabjc.2017.05.011.

[5] Rizwana H, Alwhibi MS, Aldarsone HA, Awad MA, Soliman DA, Bhat RS. Green synthesis, characterization, and antimicrobial activity of silver nanoparticles prepared using Trigonella foenum-graecum L. leaves grown in Saudi Arabia. Green Process Synth. 2021;10:421-9. doi: http://dx.doi.org/10.1515/ gps-2021-0043.

[6] Iravani S, Korbekandi H, Mirmohammadi SV, Zolfaghari B. Synthesis of silver nanoparticles: chemical, physical and biological methods. Res Pharm Sci. 2014;9(6):385-406.

[7] Kumari S, Tyagi M, Jagadevan S. Mechanistic removal of environmental contaminants using biogenic nano-materials. Int J Env Sci Technol. 2019;16:7591-606. doi: 10.1007/s13762019-02468-3.

[8] Rana A, Yadav K, Jagadevan S. A comprehensive review on green synthesis of nature-inspired metal nanoparticles: mechanism, application and toxicity. J Clean Prod. 2020;272:122880. doi: 10.1016/j.jclepro.2020.122880. ISSN 0959-6526.

[9] Jha A, Prasad K, Prasad K, Kulkarni AR. "Plant system: nature's nanofactory”. Colloids Surf B Biointerfaces. 2009;73:219-23.

[10] Ahmed S, Ahmad M, Swami BL, Ikram S. Plants extract mediated synthesis of silver nanoparticles for antimicrobial applications: a green expertise. J Adv Res. 2016;7:17-28.

[11] Singh P, Kim YJ, Zhang D, Yang DC. Biological synthesis of nanoparticles from plants and microorganisms. Trends Biotechnol. 2016;34(7):588-99. doi: 10.1016/ j.tibtech.2016.02.006.

[12] Alwhibi MS, Soliman DA, Awad MA, Alangery AB, Al Dehaish H, Alwasel YA. Green synthesis of silver nanoparticles: characterization and its potential biomedical application. Green Process Synth. 2021;10:412-20.

[13] Rauf A, Ahmad T, Khan A, Maryam M, Uddin G, Ahmad B, et al. Green synthesis and biomedicinal applications of silver and gold nanoparticles functionalized with methanolic extract of Mentha longifolia. Artif Cell Nanomed Biotechnol. 2021;49(1):194-203. To link to this article doi: 10.1080/ 21691401.2021.1890099.

[14] Zargari A. Herbal medicines. 1st edn. Tehran: Publication of Tehran University; 1990. p. 14-8.

[15] Chalchat JC, Gorunovic MS, Maksimovic ZA, Petrovic SD. Essential oil of wild growing Mentha pulegium L. from yugoslavia. J Essent Oil Res. 2000;12:598-600.
[16] Harley RM, Atkins S, Budantsev AL, Cantino PD, Conn BJ, Grayer R, et al. Labiatae. In: Kadereit JW, editors. Flowering plants-dicotyledons. the families and genera of vascular plants. Vol. 7. Berlin, Heidelberg: Springer; 2004. p. 167-275. doi: 10.1007/978-3-642-18617-2_11.

[17] Mimica-Dukic N, Bozin B. Mentha I. Species (Lamiaceae) as promising sources of bioactive secondary metabolites. Curr Pharm Des. 2008;14:3141-50.

[18] Khonche A, Fallah Huseini H, Abdi H, Mohtashami R, Nabati F, Kianbakht S. Efficacy of Mentha pulegium extract in the treatment of functional dyspepsia: a randomized double-blind placebo-controlled clinical trial. J Ethnopharmacol. 2017;206:267-73. doi: 10.1016/j.jep.2017.05.026.

[19] Teixeira B, Marques A, Ramos C, Batista I, Serrano C, Matos O, et al. European pennyroyal (Mentha pulegium) from Portugal: chemical composition of essential oil and antioxidant and antimicrobial properties of extracts and essential oil. Ind Crop Prod. 2012;36:81-7.

[20] Mahboubi M, Haghi G. Antimicrobial activity and chemical composition of Mentha pulegium L. essential oil. J Ethnopharmacol. 2008;119:325-7.

[21] Ibrahim AK. New terpenoids from Mentha pulegium L. and their antimicrobial activity. Nat Prod Res. 2013;27:691-6.

[22] Romero-Jiménez M, Campos-Sánchez J, Analla M, MuñozSerrano A, Alonso-Moraga A. Genotoxicity and anti-genotoxicity of some traditional medicinal herbs. Mutat Res. 2005;585:147-55.

[23] Kogiannou DA, Kalogeropoulos N, Kefalas P, Polissiou MG, Kaliora AC. Herbal infusions; their phenolic profile, antioxidant and anti-inflammatory effects in HT29 and PC3 cells. Food Chem Toxicol. 2013;61:152-9.

[24] Kim SW, Jung JH, Lamsal K, Kim YS, Min JS, Lee YS. Antifungal effects of silver nanoparticles (AgNPs) against various plant pathogenic fungi. Mycobiol. 2012;40:53-8.

[25] Ibrahim E, Luo J, Ahmed T, Wu W, Yan C, Li B. Biosynthesis of silver nanoparticles using onion endophytic bacterium and its antifungal activity against rice pathogen Magnaporthe oryzae. J Fungi (Basel). 2020;6:294. doi: 10.3390/jof6040294.

[26] Rizwana H. Postharvest control of anthracnose lesions and its causative agent, Colletotrichum musae by some oils. Cell Mol Biol (Noisy-le-grand). 2018;64:52-8. doi: 10.14715/cmb/ 2018.64.4.9. PMID: 29641375.

[27] Boken J, Khurana P, Thatai S, Kumar D, Prasad S. Plasmonic nanoparticles and their analytical applications: a review. Appl Spectrosc Rev. 2017;52(9):774-820.

[28] Kelly KL, Coronado E, Zhao LL, Schatz GC. -e optical properties of metal nano particles: the influence of size, shape and dielectric environment. J Phys Chem B. 2003;107(3):668-77.

[29] Rajkumar T, Sapi A, Das G, Debnath T, Ansari A, Patra JK. Biosynthesis of silver nanoparticle using extract of Zea mays (corn flour) and investigation of its cytotoxicity effect and radical scavenging potential. JPPBEG. 2019;193:1-7.

[30] Awad AM, Salem NM, Abdeen AO. Green synthesis of silver nanoparticles using carob leaf extract and its antibacterial activity. Int J Ind Chem. 2013;4(1):1-6.

[31] Rad SS, Sani AM, Mohseni S. Biosynthesis, characterization and antimicrobial activities of zinc oxide nanoparticles from leaf extract of Mentha pulegium (L.). Microb Pathog. 2019;131:239-45. 
[32] Kora AJ, Beedu SR, Jayaraman A. Size-controlled green synthesis of silver nanoparticles mediated by gum ghatti (Anogeissus latifolia) and its biological activity. Org Med Chem Lett. 2012;2(1):17. doi: 10.1186/2191-2858-2-17.

[33] Gupta A, Koirala AR, Gupta B, Parajuli N. Improved method for separation of silver nanoparticles synthesized using the Nyctanthes arbor-tristis shrub. ACMY. 2019;3(1):35-42.

[34] Das B, Dash SK, Mandal D, Ghosh T, Chattopadhyay S, Tripathy S, et al. Green synthesized silver nanoparticles destroy multidrug resistant bacteria via reactive oxygen species mediated membrane damage. Arab J Chem. 2017;10(6):862-76. doi: 10.1016/j.arabjc.2015.08.008.

[35] Moteriya P, Chanda S. Green synthesis of silver nanoparticles from Caesalpinia pulcherrima leaf extract and evaluation of their antimicrobial, cytotoxic and genotoxic potential (3-in-1 system). J Inorg Organomet Polym. 2020;30:3920-32. doi: 10.1007/s10904020-01532-7.

[36] Kelkawi AHA, Abbasi Kajani A, Bordbar AK. Green synthesis of silver nanoparticles using Mentha pulegium and investigation of their antibacterial, antifungal and anticancer activity. IET Nanobiotechnol. 2017;11(4):370-6. doi: 10.1049/ietnbt.2016.0103. PMID: 28530184.

[37] Clayton KN, Salameh JW, Wereley ST, Kinzer-Ursem TL. Physical characterization of nanoparticle size and surface modification using particle scattering diffusometry. Biomicrofluidics. 2016;10(5):054107. doi: 10.1063/1.4962992.
[38] Kaviya S, Santhanalakshmi J, Viswanathan B, Muthumary J, Srinivasan K. Biosynthesis of silver nanoparticles using citrus sinensis peel extract and its antibacterial activity. Spectrochim Acta A Mol Biomol Spectrosc. 2011;79(3):594-8. doi: 10.1016/j.saa.2011.03.040.

[39] Duran N, Marcato P, Alves OL, De Sousa GIH, Esposito E. Mechanistic aspects of biosynthesis of silver nanoparticles by several Fusarium oxysporum strains. J Nanobiotechnol. 2005;3:8. doi: 10.1186/1477-3155-3-8.

[40] Bera RK, Mandal SM, Retna Raj C. Antimicrobial activity of fluorescent Ag nanoparticles. Lett Appl Microbiol. 2014;58:520-6.

[41] Khatami M, Sharifi I, Marcos AL. Waste-grass-mediated green synthesis of silver nanoparticles and evaluation of their anticancer, antifungal and antibacterial activity. Green Chem Lett Rev. 2018;11(2):125-34.

[42] Kim KJ, Sung WS, Suh BK, Moon SK, Choi JS, Kim JG, et al. Antifungal activity and mode of action of silver nano-particles on Candida albicans. Biometals. 2009;22(2):235-42.

[43] Lamsal K, Kim SW, Jung JH, Kim YS, Kim YS, Lee YS. Application of silver nanoparticles for the control of colletotrichum species in vitro and pepper anthracnose disease in field. Mycobiol. 2011;39(3):194-9.

[44] Gallardo RV, Cruz JFO, Ortíz-Rodriguez 00. Fungicidal effect of silver nanoparticles on toxigenic fungi in cocoa. FITOPATOLOGIA. Pesq Agropec Bras. 2016;51(12):1929-36. doi: 10.1590/ S0100-204X2016001200003. 